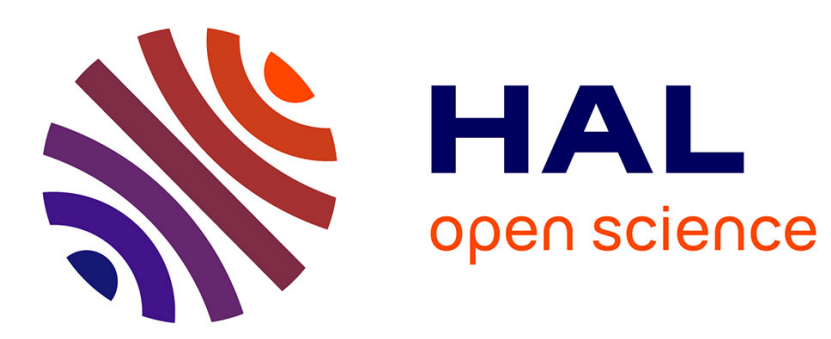

\title{
Carbohydrate-Decorated PCL Fibers for Specific Protein Adhesion
}

\author{
Anica Lancuški, Frederic Bossard, Sebastien Fort
}

\section{To cite this version:}

Anica Lancuški, Frederic Bossard, Sebastien Fort. Carbohydrate-Decorated PCL Fibers for Specific Protein Adhesion. Biomacromolecules, 2013, 14 (6), pp.1877-1884. 10.1021/bm400263d . hal01170726

\section{HAL Id: hal-01170726 \\ https://hal.science/hal-01170726}

Submitted on 16 Jan 2019

HAL is a multi-disciplinary open access archive for the deposit and dissemination of scientific research documents, whether they are published or not. The documents may come from teaching and research institutions in France or abroad, or from public or private research centers.
L'archive ouverte pluridisciplinaire HAL, est destinée au dépôt et à la diffusion de documents scientifiques de niveau recherche, publiés ou non, émanant des établissements d'enseignement et de recherche français ou étrangers, des laboratoires publics ou privés. 


\title{
Carbohydrate-Decorated PCL Fibers for Specific Protein
}

\author{
Adhesion \\ Anica Lancuški, ${ }^{1,2}$ Frédéric Bossard ${ }^{2}$, Sébastien Fort, ${ }^{1 *}$ \\ ${ }^{1}$ Centre de Recherches sur les Macromolécules Végétales, UPR, CNRS, 5301, BP53, \\ 38041 Grenoble Cedex 9, France $\dagger$ \\ ${ }^{2}$ Laboratoire Rhéologie et Procédés, Université Joseph-Fourier - Grenoble Institut National \\ Polytechnique, 1301 rue de la piscine, 38041 Grenoble Cedex 9, France \\ † Affiliated with Université de Grenoble, member of Institut de Chimie Moléculaire de \\ Grenoble and member of the Polynat Carnot Institute
}

\begin{abstract}
Ultra-fine biocompatible fibers decorated with carbohydrates were prepared by electrospinning. Both bulk- and surface- modification approaches have been devised and compared in terms of practicability and grafting density along the fibrous mats. On one hand, bulk-functionalized fibers were prepared by electrospinning of native and galactose-modified PCL polymers. The size and morphology of the resulting fibers was strongly influenced by the sugar-PCL content as observed by electron microscopy. Successful surface modification was evidenced by water contact angle measurements, but a rather low carbohydrate density was attained, as indicated by a colorimetric quantification. On the other hand, efficient and versatile surface-glycosylation was achieved after modification of azido-functionalized electrospun fibers by CuAAC click-chemistry. Homogeneous ultra-fine PCL fibers, decorated with azide functions, have been made highly hydrophilic upon coupling with propargyl-mannose and propargyl-galactose derivatives. Specific adhesion of lectins further attested good bioavailability of the
\end{abstract}


carbohydrate surface-residues, suggesting interesting perspectives of the latter approach in the development of bioactive materials for tissue engineering.

KEYWORDS: electrospinning, fibers, polycaprolactone, click chemistry, carbohydrates, lectins

\section{INTRODUCTION}

Electrospun nonwoven scaffolds represent advantageous materials for medical and bioengineering purposes due to their high surface area and small diameter fibers. ${ }^{1,2}$ As a consequence, electrospun fibers are often employed for wound dressing, ${ }^{3}$ drug delivery, ${ }^{4}$ sutures or tissue engineering..$^{5-7}$ The application diversity of these fibrous mats is, however, often conditioned by their initial physico-chemical properties. Poly( $\varepsilon$-caprolactone) (PCL), as biodegradable and biocompatible polymer with low cytotoxicity, has been widely adopted as synthetic biopolymer for medical applications. ${ }^{8-10}$ Modification of PCL-based materials have also been reported in order to improve their hydrophilic properties and to achieve a friendly interface for living cells. Recent works emphasized that surface modification of electrospun fibers with chemical functions or biomolecules strongly influences protein binding and, therefore, cell-material interactions. ${ }^{11,12}$ Wet chemical methods, due to their simplicity and availability, have been often adopted for PCL fibers' surface modification. Mobarakeh et al. ${ }^{6}$ reported the surface modification of PCL fibers with Matrigel ${ }^{\mathrm{TM}}$ (a soluble sterile extract rich in laminin, collagen IV, fibronectin and heparin sulphate proteoglycans) by partial alkaline hydrolysis of the scaffold and subsequent covalent amide bond formation. Alternatively, gelatin-functionalized PCL film surfaces were developed by a "grafting-from" polymerization approach. Such modification required prior chemical activation of the PCL chains by aminolysis. ${ }^{10}$ Click chemistry has 
recently received significant attention to modify material surfaces, films ${ }^{13}$ or fibers ${ }^{14}$, in order to generate a specific functionality. For example, cellulose surface modification has been efficiently achieved by means of thiol-ene reaction ${ }^{15}$ or azide-alkyne cycloaddition ${ }^{16}$ under heterogeneous conditions. $\mathrm{Xu}$ et al. ${ }^{17}$ highlight click chemistry as a convenient method for the synthesis of saccharide-terminated poly( $\varepsilon$-caprolactone $)$ s as potential drug carriers.

Carbohydrates perform numerous roles in living organisms. They serve for the storage of energy, as structural components, but they are also involved in diverse cellular processes, enabling communication, proliferation, differentiation. Functionalization of polymers such as polyolefins with sugars has been explored periodically as a possible way to improve their biodegradability..$^{18}$ Over time, carbohydrate-conjugated polymers have attracted attention for their biomedical applications. R. Gentsch et al. ${ }^{19}$ investigated the surface functionalization of PCL/PPfpMA fibers with monosaccharides and showed that these functionalized fibers trigger specific interactions with antigen-presenting cells, e.g., macrophages. K.-N. Chua et al. ${ }^{20}$ demonstrated that galactose-conjugated nanofiber meshes promote cell-substrate interaction, suggesting potential scaffold application in liver tissue engineering. Equally, sugar-conjugated polymers were employed for immobilization of proteins, ${ }^{21}$ as cell's surface mimics, ${ }^{22}$ cell adhesion as well as for many pharmacological and biomedical applications. ${ }^{23}$

Yet, only recently, attention has been paid to overcome the non-specific protein adsorption on electrospun fibers. ${ }^{12,24}$ A significant step towards specific protein adsorption using biofunctionalized polymeric fibers was made by D. Grafahrend and coworkers. They highlighted the importance of the polymer choice for electrospinning as well as the choice of active species at the fibrous surface. ${ }^{24-28}$ In the present study, we have investigated a versatile approach for surface functionalization of electrospun fibrous mats that would 
allow efficient conjugation of carbohydrates, proteins and other biomolecules towards specific protein adhesion. Two different strategies have been devised. In a first approach, bulk fiber's glycosylation has been carried by electrospinning carbohydrate-modified $\alpha, \omega-$ poly( $\varepsilon$-caprolactone)-diol $M_{\mathrm{n}} 2000 \mathrm{~g} \mathrm{~mol}^{-1}\left(\mathrm{PCL}_{2}-\mathrm{Gal}\right)$ and native high molecular weight poly( $\varepsilon$-caprolactone) $M_{\mathrm{n}} 70000-90000 \mathrm{~g} \mathrm{~mol}^{-1}$ (PCL 80$)$. The second strategy relied on the surface functionalization by click chemistry of recently reported electrospun azido-fibers. ${ }^{29}$ Hydrophilicity of the resulting fibers as well as bioavailability of the carbohydrates were evaluated by contact angle measurements and enzyme-linked lectin assays, respectively. A debate followed about the optimal path for obtaining carbohydrates-decorated ultra-fine fibers by comparing the bulk- and the surface- functionalization processes.

\section{EXPERIMENTAL SECTION}

Materials. Poly( $\varepsilon$-caprolactone) (PCL80) $M_{\mathrm{n}} 70000-90000 \mathrm{~g} \mathrm{~mol}^{-1}$, copper(II) sulfate pentahydrate $\left(\mathrm{CuSO}_{4} \cdot 5 \mathrm{H}_{2} \mathrm{O}\right)$, sodium ascorbate, calcium chloride $\left(\mathrm{CaCl}_{2}\right)$, magnesium chloride $\left(\mathrm{MgCl}_{2}\right)$, manganese chloride $\left(\mathrm{MnCl}_{2}\right)$, TWEEN 20, phosphate buffered saline (PBS) 10x concentrate $(\mathrm{pH}=7.2-7.6$ at $1: 10$ dilution), $\beta$-galactosidase (Aspergillus oryzae), 3-amino-9-ethylcarbazole (AEC) chromogen kit, Concanavalin A-peroxidase conjugate (HRP-ConA), Arachis hypogaea-peroxidase conjugate (HRP-PNA) and all organic solvents were purchased from Sigma Aldrich and used without further purification. $\alpha, \omega$-Poly $\left(\varepsilon\right.$-caprolactone)-diol $\left(\mathrm{PCL}_{2}\right), M_{\mathrm{n}} 2000 \mathrm{~g} \mathrm{~mol}^{-1}$ (Sigma), was recrystallized from diethyl ether prior to use.

Electrospinning. Electrospinning process was performed with a horizontal setup - a $5 \mathrm{~mL}$ syringe was filled with polymer solution slightly above the overlap concentration and placed on the syringe pump with the blunt 21-gouge needle attached. Flow rate was controlled by a syringe pump (KD Scientific series 200, USA) in the range from 0.01 to 
$0.03 \mathrm{~mL} / \mathrm{min}$. Fibers were collected directly on aluminum foil. The distance between needle tip and collector was fixed at $15 \mathrm{~cm}$. Applied voltage (dual high voltage power supply, $\pm 30 \mathrm{kV}$, iseq GMBH Germany) ranged from 11 to $15 \mathrm{kV}$. All experiments were done at room temperature. The relative humidity noted was between 30 and 55\%. For the bulk-functionalization purposes, $\mathrm{PCL}_{2}-\mathrm{Gal}$ was blended with $\mathrm{PCL}_{80}$ in ratio 20:80 and 40:60 in dichloromethane/methanol (DCM/MeOH 4/1 v/v) solvent mixture and electrospun. For the surface-functionalization, f-PCL-N $3-20,-40$ and -60 were prepared as reported previously. ${ }^{29}$ Briefly, $\mathrm{PCL}_{80}$ and $\mathrm{PCL}_{2}-\mathrm{N}_{3}$ were blended, using the same solvent mixture, in order to obtain 20,40 or $60 \mathrm{wt} \%$ of $\mathrm{PCL}_{2}-\mathrm{N}_{3}$ in the blend and electrospun.

Synthesis of $\alpha, \omega$-Galactoside-poly( $\varepsilon$-caprolactone) $\quad$ (PCL2-Gal) and its Electrospinning with PCL80. $\alpha, \omega$-Azide-poly ( $\varepsilon$-caprolactone) $\left(\mathrm{PCL}_{2}-\mathrm{N}_{3}\right)$ was prepared as reported previously in the literature. ${ }^{29} \mathrm{PCL}_{2}-\mathrm{N}_{3}(1.5 \mathrm{~g}, 0.72 \mathrm{mmol})$ was then involved into click reaction with propargyl- $\beta$-D-galactoside (see Supporting Information for its detailed synthesis) (1.57 g, $7.2 \mathrm{mmol}, 5$ equiv. per azide group) in tetrahydrofuran/water $(1 / 1 \mathrm{v} / \mathrm{v})$ solvent mixture $(100 \mathrm{~mL})$ at $40{ }^{\circ} \mathrm{C}$ for $48 \mathrm{~h}$ in the presence of $\mathrm{CuSO}_{4} \cdot 5 \mathrm{H}_{2} \mathrm{O}(0.36 \mathrm{~g}, 1.44$ mmol, 1 equiv. per azide group) and sodium ascorbate $(0.28 \mathrm{~g}, 1.44 \mathrm{mmol}, 1$ equiv. per azide group). Reaction mixture was concentrated in rotavapor, dissolved in $2 \mathrm{~mL}$ of $\mathrm{N}, \mathrm{N}$ dimethylformamide (DMF) and precipitated in $40 \mathrm{~mL}$ of toluene. The solid was filtrated and dried under vacuum to provide $\mathrm{PCL}_{2}-\mathrm{Gal}(1.6 \mathrm{~g})$ in $94 \%$ yield. $\mathrm{PCL}_{2}-\mathrm{Gal}$ was then blended with $\mathrm{PCL}_{80}$ in 20:80 and 40:60 w/w ratio in $\mathrm{DCM} / \mathrm{MeOH}(4 / 1 \mathrm{v} / \mathrm{v})$ solvent mixture and electrospun. Resulting fibers: $\mathrm{f}-\mathrm{PCL}_{20}-\mathrm{Gal}_{\mathrm{B}}$ and $\mathrm{f}-\mathrm{PCL}_{40}-\mathrm{Gal}_{\mathrm{B}}$ stand for a blend of bulk-functionalized $\mathrm{PCL}_{2}-\mathrm{Gal}$ and $\mathrm{PCL}_{80}$ polymers in ratios 20/80 and 40/60, respectively.

\section{Surface-Grafting of Monosaccharides onto the f-PCL-N3 Fibers Using Heterogeneous}

Click Chemistry. Monosaccharides, propargyl- $\alpha$-D-mannoside (see Supporting Information for detailed synthesis) and propargyl- $\beta$-D-galactoside were conjugated onto 
the surface of f-PCL- $\mathrm{N}_{3}-20,-40$, and -60 fibers using CuAAC click chemistry coupling. Resulting fibers were labeled as f-PCL $20-\mathrm{Gal}_{\mathrm{s}}$, f-PCL $40-\mathrm{Gal}_{\mathrm{s}}$, and f-PCL $60-\mathrm{Gal}_{\mathrm{s}}$ for galactose surface-functionalized, while f-PCL $20-\mathrm{Man}_{\mathrm{S}}$, f-PCL $40-\mathrm{Man}_{\mathrm{S}}$, and f-PCL60-Man correspond to the mannose surface-functionalized fibers from f-PCL-N $3-20,-40$, and -60 fibrous mats, respectively. Click reaction between propargyl-monosaccharides and azidofibers in heterogeneous phase is described on the example of $\mathrm{f}-\mathrm{PCL}_{20}-\mathrm{Gal}_{\mathrm{s}}$ preparation. $\mathrm{f}$ PCL-N $\mathrm{N}_{3}-20$ fibers $(20 \mathrm{mg}$ ) were put in a microcentrifuge tube containing $4 \mathrm{~mL}$ of distilled water, and then $54.7 \mu \mathrm{L}$ (10 equiv. per azide group on the surface, as estimated by the ninhydrin assay $^{29}$ ) of $0.1 \mathrm{M}$ aqueous solution of propargyl- $\beta$-D-galactoside, $21.9 \mu \mathrm{L}$ $\mathrm{CuSO}_{4} \cdot 5 \mathrm{H}_{2} \mathrm{O}$ in distilled water $(0.1 \mathrm{M}, 4$ equiv. per azide group) and $21.9 \mu \mathrm{L}$ of sodium ascorbate in distilled water ( $0.1 \mathrm{M}, 4$ equiv. per azide group) were added. Reaction mixture was stirred for $24 \mathrm{~h}$ at room temperature and then fibers were thoroughly washed with distilled water. f-PCL $40-\mathrm{Gal}_{\mathrm{S}}$ and $\mathrm{f}-\mathrm{PCL}_{60}-\mathrm{Gal}_{\mathrm{S}}$ were prepared from f-PCL- $\mathrm{N}_{3}-40$ and fPCL-N $\mathrm{N}_{3}-60$, respectively, following the same procedure while keeping the same molar ratio. f-PCL $20-\mathrm{Man}_{\mathrm{S}}$, f-PCL40-Mans and f-PCL60-Mans functionalized fibers were prepared similarly as f-PCL-Gals fibers by replacing propargyl- $\beta$-D-galactoside with propargyl- $\alpha$-Dmannoside.

Characterization. Infrared Spectroscopy. ATR-FTIR spectra of the fibers were recorded in the transmission mode on a Perkin-Elmer 1720X FTIR instrument using single reflection diamond ATR.

NMR Spectroscopy. ${ }^{1} \mathrm{H}$ and ${ }^{13} \mathrm{C}$ NMR spectra were obtained with a Bruker AVANCE 400 MHz with 5mm QNP probe at $298 \mathrm{~K}$.

Viscosity. Viscosity measurements of polymer solutions were done using HAAK MARS III controlled-stress rheometer equipped with cone-plate geometry (titan cone, characterized by a diameter of $60 \mathrm{~mm}, 1^{\circ}$ angle and $53 \mu \mathrm{m}$ gap). Flow measurements were 
performed at $10{ }^{\circ} \mathrm{C}$ and an anti-evaporation system was used to reduce the solvent evaporation.

Electron-Microscopy Measurement. Field Emission Scanning Electron Microscope (FESEM ZEISS ULTRA55) was used for observing the morphology of the fibers at $1 \mathrm{kV}$ accelerating voltage, $5 \mathrm{~mm}$ of working distance and at magnifications of 500, 1000 and 2000 times. All samples were sputter coated with Pt of $1 \mathrm{~nm}$ thickness. Average fiber diameters of the electrospun fibers, were obtained as a mean value of 150 different diameters measured by ImageJ software.

Water Contact Angle (WCA). WCA measurements were done in the sessile-drop mode at $20{ }^{\circ} \mathrm{C}$ using Dataphysics Intruments $\mathrm{Gmb}$ goniometer. Nonwoven fibrous meshes were fixed onto an object slide using adhesive tapes at the sides of the sample. The volume of the applied droplet is $1 \mu \mathrm{L}$. The resulting value of each measurement represents the average value of the left and the right contact angle. The images of the water droplet on electrospun fiber meshes and the corresponding contact angle were recorded from droplet deposition onto the fibers until its stabilization.

Dynamic Light Scattering (DLS). DLS measurements were performed using a ALV/CGS$8 \mathrm{~F}$ goniometer, equipped with a linearly polarized $\mathrm{He} / \mathrm{Ne}$ laser $(\lambda=632.8 \mathrm{~nm}, \mathrm{P}=35 \mathrm{~mW})$ and an ALV multiple $\tau$ correlator with a $125 \mathrm{~ns}$ initial sampling time. The unfiltered mixtures were measured at $25{ }^{\circ} \mathrm{C}$ for a typical counting time of $200 \mathrm{~s}$ at a scattering angle of $90^{\circ}$. The size distributions were obtained with the CONTIN analysis of the autocorrelation functions and particularly with the Stokes-Einstein equation as detailed elsewhere. ${ }^{30,31}$ The viscosity and refractive index of the DCM/MeOH $4 / 1$ solvent mixture alone are calculated to be $0.466 \mathrm{cP}$ and 1.398 , respectively. ${ }^{32-34}$

Carbohydrate quantification. Fiber surface carbohydrates were quantified by the Dubois assay. ${ }^{35}$ This assay was carried out under heterogeneous conditions directly on the fibers 
for surface-functionalized ones. For the bulk-modified fibers, Dubois assay was carried out on the supernatant after enzymatic hydrolysis of the surface carbohydrates.

Quantification of the surface carbohydrates on $f$-PCL-Gals and f-PCL-Mans. Sugardecorated fibers $(2 \mathrm{mg})$ were dispersed in $100 \mu \mathrm{L}$ of distilled water and $100 \mu \mathrm{L}$ of phenol solution ( $5 \mathrm{w} / \mathrm{v} \%)$ was added followed by addition of $1000 \mu \mathrm{L}$ of $96 \%$ of sulfuric acid. The solution was vigorously agitated for $15 \mathrm{~min}$ at room temperature and absorbance at $490 \mathrm{~nm}$ was measured with UVIKON $810 \mathrm{UV}$-vis spectrophotometer. The concentration of sugar was determined by reference to a calibration curve with galactose as a standard for $\mathrm{f}$ PCL-Gals fibers and mannose as a standard for f-PCL-Mans fibers.

Quantification of surface carbohydrates on $f$-PCL-Gal . $_{\text {f-PCL-Gal }}$ fibers (4 mg) were put in a microcentrifuge tube containing $500 \mu \mathrm{L}$ acetate buffer $(0.2 \mathrm{M}, \mathrm{pH}=4.50)$ and carbohydrate groups were hydrolyzed by a large excess of $\beta$-galactosidase from Aspergillus oryzae (Sigma) $\left(25 \mu \mathrm{L}, 200\right.$ units/mL in PBS 1:10 dilution), at $30{ }^{\circ} \mathrm{C}$ with gentle stirring. Quantification of carbohydrates released from the fiber surface was achieved by standard Dubois assay at different times $(4,24,48$ and 72 h) on $50 \mu \mathrm{L}$ of supernatant.

Enzyme-Linked Lectin Assay (ELLA). ELLA test was done to determine the presence and bioavailability of the carbohydrates on the fiber surface. Horseradish peroxidase-labeled lectin (HRP) from Canavalia ensiformis (HRP-ConA, mannose-binding lectin) was dissolved in PBS (1:10 dilution) in order to obtain $250 \mathrm{mg} / \mathrm{mL}$ solution. Horseradish peroxidase-labeled lectin from Arachis hypogaea (HRP-PNA, galactoside-binding lectin) was dissolved in PBS (1:10) to obtain $200 \mathrm{mg} / \mathrm{mL}$ solution. Carbohydrate bulk- and surface-functionalized fibers, f-PCL-Gal ${ }_{B}$ and f-PCL-Gals as well as native fibers, $\mathrm{f}_{\mathrm{PC}} \mathrm{PC}$, were placed separately in screw-capped test tubes and left for 5 min at room temperature in PBS (1:10 dilution, $\mathrm{pH}=7.2-7.6)$ containing $2 \mathrm{v} / \mathrm{v} \%$ of TWEEN 20 for blocking extra 
binding sites. The fibers were washed in PBS (1:10 dilution) and then put in a $1 \mathrm{~mL}$ of fresh PBS (1:10 dilution) containing $25 \mu \mathrm{L}$ of HRP-PNA solution $(200 \mu \mathrm{g} / \mathrm{mL})$, with 1 $\mathrm{mM} \mathrm{MnCl} 2,1 \mathrm{mM} \mathrm{MgCl} 2$ and $1 \mathrm{mM} \mathrm{CaCl}_{2}$ for $16 \mathrm{~h}$ at $20^{\circ} \mathrm{C}$. Fibers were then thoroughly washed with PBS (1:10 dilution) and then put in $4 \mathrm{~mL}$ of deionized water where 2 drops of (2.5 M, pH=5.0) acetate buffer, 1 drop of AEC Chromogen Sigma (3-amino-9ethylcarbazole), a perceptible peroxidase substrate, provides red chromogen deposition on lectin-modified surfaces) and 1 drop of 3\% hydrogen peroxide were added. After 10-15 minutes, the reddish coloration of the f-PCL-Gal ${ }_{\mathrm{B}}$ and f-PCL-Gals fibers was observed. Similar procedure was followed for f-PCL-Mans fibers with the difference of the lectin used. For $\alpha$-mannose recognition, $25 \mu \mathrm{L}$ of HRP-ConA solution $(200 \mu \mathrm{g} / \mathrm{mL})$ was used.

\section{RESULTS AND DISCUSSION}

The present study was focused on the functionalization of electrospun fibers with carbohydrates, by bulk and surface modification approaches (Scheme 1), and on the evaluation of their protein adhesion properties. Bulk glycosylated fibers were envisaged by electrospinning of galactosylated poly( $\varepsilon$-caprolactone) $\left(\mathrm{PCL}_{2}-\mathrm{Gal}\right)$ and bare $\mathrm{PCL}_{80}$ while surface-modified fibers were considered by click chemistry conjugation of the sugar groups onto electrospun azido-PCL fibers. 


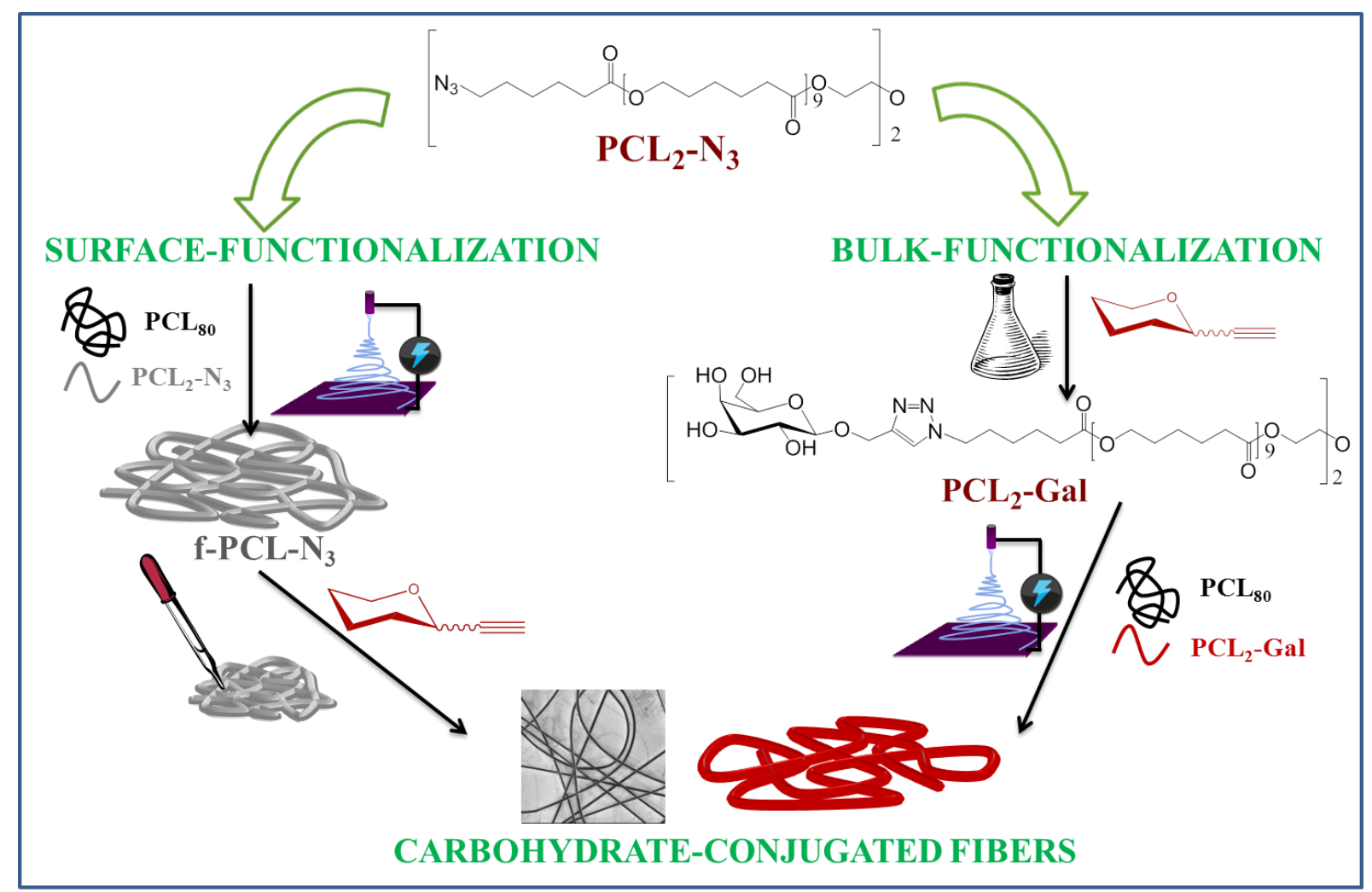

Scheme 1. Schematic representation of the bulk- and surface-functionalization processes towards carbohydrate-decorated fibers

\subsection{Bulk Functionalization of PCL Electrospun Fibers}

Prior to electrospinning, $\mathrm{PCL}_{2}$ chains were activated at both ends by azido groups as recently reported in the literature ${ }^{29}$ and functionalized with galactosyl ligands through copper-catalyzed Huisgen cycloaddition. Successful formation of $\mathrm{PCL}_{2}-\mathrm{Gal}$ was confirmed by mass spectrometry and by ${ }^{1} \mathrm{H}$ NMR with characteristic signals of the triazolyl group and of the sugar anomeric proton at 8.03 and $4.81 \mathrm{ppm}$ respectively (Figure 1). 


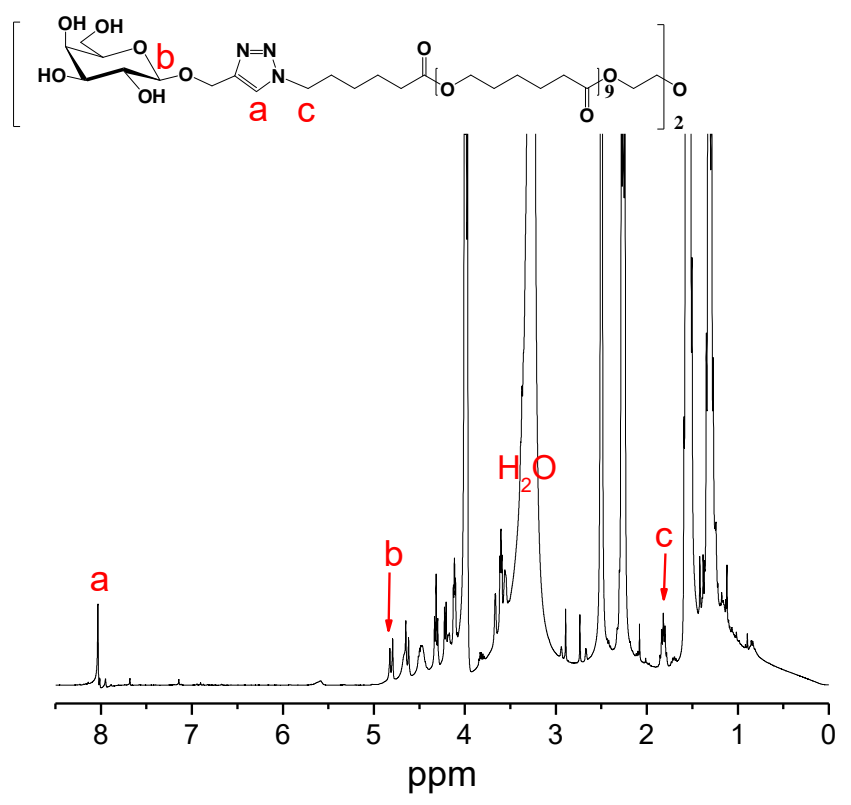

Figure 1. ${ }^{1} \mathrm{H}$ spectrum of the $\mathrm{PCL}_{2}-\mathrm{Gal}$ in DMSO- $d_{6}$

Electrospinning, in dichloromethane/methanol (DCM/MeOH 4/1 v/v), of 20:80 and 40:60 (wt/wt) mixtures of $\mathrm{PCL}_{2}-\mathrm{Gal}$ and $\mathrm{PCL}_{80}$ respectively afforded f-PCL ${ }_{20}-\mathrm{Gal}_{\mathrm{B}}$ and $\mathrm{f}-$ PCL40-GalB fibrous mats. DCM is a good solvent for poly( $\varepsilon$-caprolactone); volatile and thus advantageous for electrospinning purposes. However, in order to increase the conductivity of the electrospinning solution and solubility of monosaccharides, a small amount of conducting solvent (herein methanol) is usually used. ${ }^{36}$

Field Emission Scanning Electron Microscopy (FE-SEM) observations showed rather interesting fiber-diameter trend (Figure 2, A-C). While the average diameter of electrospun

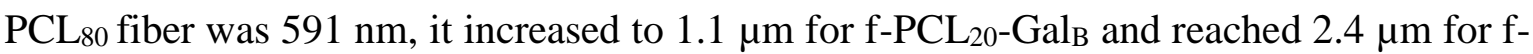
$\mathrm{PCL}_{40}-\mathrm{Gal}_{\mathrm{B}}$ fibers. Concurrently, the increasing content of $\mathrm{PCL}_{2}-\mathrm{Gal}$ reduced the ability to electrospin the blend and led to heterogeneous fiber diameters (Figure 2D). Water contact angles (WCA), represented as insets in Figure 2, showed significant decrease from $130^{\circ}$ to $90^{\circ}$, for $\mathrm{f}-\mathrm{PCL}_{80}$ and $\mathrm{f}-\mathrm{PCL}_{20}-\mathrm{Gal}_{\mathrm{B}}$ fibers, respectively. These findings support the presence of galactose groups on the surface of the fibers. Unfortunately, f-PCL $40-\mathrm{Gal}_{\mathrm{B}}$ fibers did not 
allow precise contact angle measurements because of inhomogeneous layer deposition resulting from a poor electrospinnability. Nevertheless, surface carbohydrates of bulkfunctionalized fibers were further quantified by colorimetric assay. f-PCL $\mathrm{L}_{20}-\mathrm{Gal}_{\mathrm{B}}$ and $\mathrm{f}$ $\mathrm{PCL}_{40}-\mathrm{Gal}_{\mathrm{B}}$ fibers were exposed to enzymatic treatment with a $\beta$-galactosidase (Aspergillus oryzae) and the concentration of sugar released in the supernatant was determined by the Dubois assay. Surprisingly, a rather small amount (2-3 wt $\%)$ of the initial galactose content was found to be present on the fiber's surface. To exclude possible degradation of carbohydrates during the electrospinning process, a total sugar analysis in the fibers has been carried out and confirmed that about $97 \%$ of the galactose initially introduced was confined in the fiber's core.
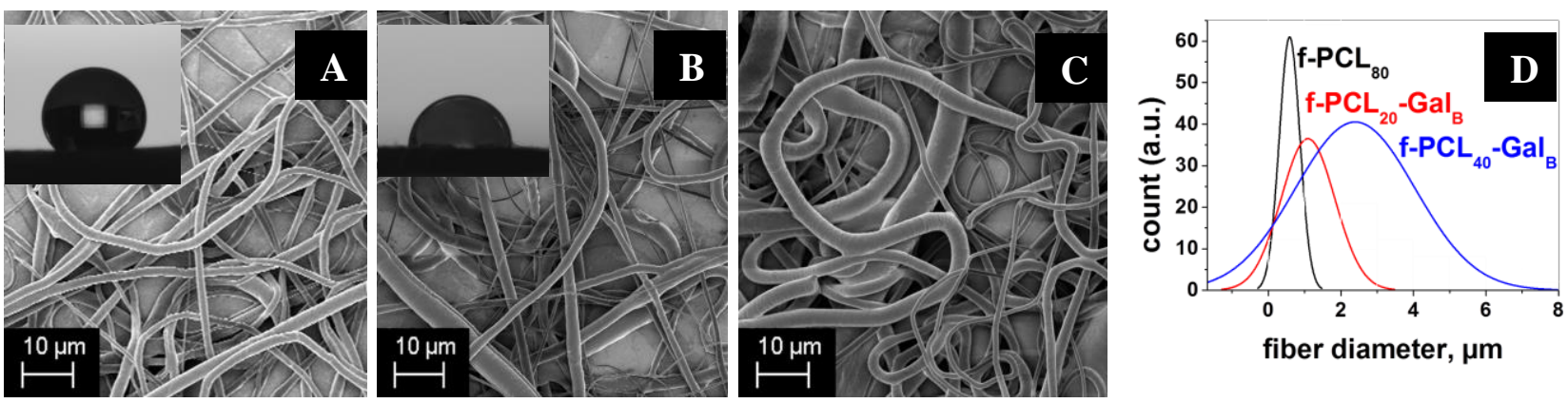

Figure 2. (A-C) FE-SEM images of Pt-coated: (A) f-PCL 80 non-derived fibers, (B) f-PCL ${ }_{20^{-}}$ $\mathrm{Gal}_{\mathrm{B}}$ and (C) f-PCL40-Gal ${ }_{\mathrm{B}}$ fibers and (D) graphical representation of their fiber diameter distributions. The insets A and B represent the water sessile drops onto the PCL 80 and f$\mathrm{PCL}_{20}-\mathrm{Gal}_{\mathrm{B}}$ fibers, respectively.

The modest surface functionalization of $\mathrm{f}-\mathrm{PCL}-\mathrm{Gal}_{\mathrm{B}}$ fibers as well as their large diameter distributions opened the question whether this trend is related to inter-, intramolecular interactions or rather polymer-solvent interactions? To interpret these results, dynamic light scattering (DLS) and viscosity measurements were carried out. On the Figure 3, representing the DLS size distributions, objects with a radius of few tens of 
micrometers are observed for the solvent mixture $\mathrm{DCM} / \mathrm{MeOH} 4 / 1$ alone. It alludes to the emulsion character of the two partially miscible solvents, with $\mathrm{MeOH}$ droplets dispersed in the DCM medium. Upon addition of $\mathrm{PCL}_{2}-\mathrm{Gal}$ in the solvent mixture, an additional pic at $R_{h} \sim 350 \mathrm{~nm}$ is observed, indicating the formation of $\mathrm{PCL}_{2}-\mathrm{Gal}$ aggregates. The DLS size distribution shown on the Figure 3 is mass-weighted; thus larger objects seem to be more present in the solution. When considering the number of particles in solution (see Supporting Information), one could realize that polymers aggregates are in fact one million times more abundant than $\mathrm{MeOH}$ droplets.

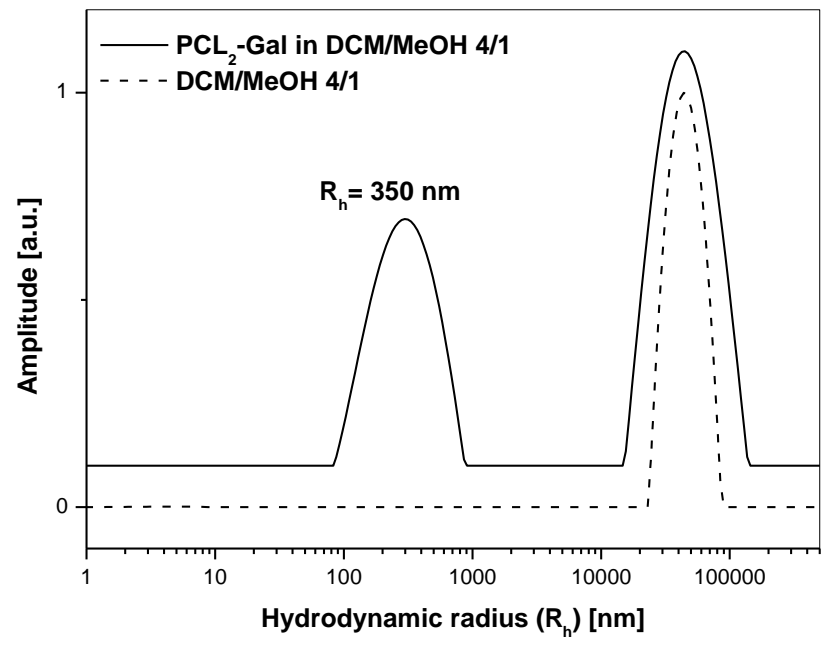

Figure 3. Size distribution of DCM/MeOH 4/1 solvent mixture alone (----) and with $\mathrm{PCL}_{2}-\mathrm{Gal}$ dissolved in it (-), at $90^{\circ}$

Viscosity measurements were performed on polymer solutions of PCL 80 (8 wt\%) and on blends $\mathrm{PCL}_{80} / \mathrm{PCL}_{2}, \mathrm{PCL}_{80} / \mathrm{PCL}_{2}-\mathrm{N}_{3}$ and $\mathrm{PCL}_{80} / \mathrm{PCL}_{2}-\mathrm{Gal}$ at ratio of 80:20 and total polymer concentration of $10 \mathrm{wt} \%$. Figure 4 shows the viscosity of polymer solutions as a function of the shear rate. $\mathrm{PCL}_{80}$ and blends of $\mathrm{PCL}_{80} / \mathrm{PCL}_{2}$ and $\mathrm{PCL}_{80} / \mathrm{PCL}_{2}-\mathrm{N}_{3}$ are Newtonian in the shear-rate range explored. As expected, the viscosity of blends is higher than the pure $\mathrm{PCL}_{80}$. The slight decrease of $\mathrm{PCL}_{80} / \mathrm{PCL}_{2}-\mathrm{N}_{3}$ viscosity compared to that of $\mathrm{PCL}_{80} / \mathrm{PCL}_{2}$ could be assigned to a decrease of the density of intermolecular hydrogen 
bonding induced by the presence of $\mathrm{N}_{3}$ groups. However, the flow behavior of the sugarconjugated $\mathrm{PCL}_{80} / \mathrm{PCL}_{2}-\mathrm{Gal}$ solution is extremely different, exhibiting a significant shearthinning behavior at low shear rates.

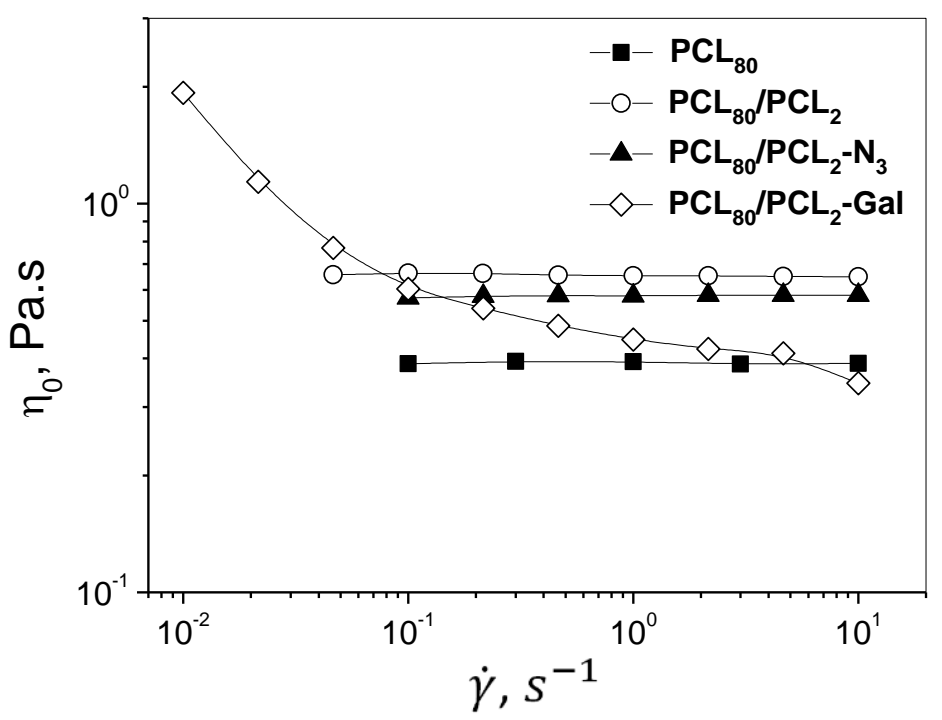

Figure 4. Zero-shear viscosity/shear rate profiles for polymer mixtures of $8 \mathrm{wt} \%$ PCL 80 and: (ロ) without $\mathrm{PCL}_{2},(\mathrm{O}) 2$ wt $\%$ of $\mathrm{PCL}_{2},(\boldsymbol{\Delta}) 2$ wt $\% \mathrm{PCL}_{2}-\mathrm{N}_{3}$ and $(\diamond) 2$ wt $\%$ of

$$
\mathrm{PCL}_{2}-\mathrm{Gal}
$$

Accordingly, it was hypothesized that the amphiphilic structure of $\mathrm{PCL}_{2}-\mathrm{Gal}$ might lead to the formation of a transient network of PLC chains. The presence of inter-chain complexes could then induce the steric interactions responsible for the significant increase in the solution viscosity and the polymer fibers' diameter, as already observed by Yu et al. ${ }^{37}$ with a mixture of phosphatidyl choline (PC) surfactant and polyvinylpyrrolidone (PVP) in chloroform. Indeed, in the solvent system of DCM (polar, aprotic, good solvent for PCL) - MeOH (polar, protic, non-solvent for PCL but good solvent for galactose) (4/1), galactosyl units of $\mathrm{PCL}_{2}-\mathrm{Gal}$ might tend to aggregate inside the methanol microemulsions, forming aggregated galactose domains in $\mathrm{MeOH}$ and PCL chain domains in 
DCM, as schematically represented in the Figure 5 . Gentsch et al. ${ }^{38}$ already observed the aggregation phenomenon of the low-molecular-weight peptide-PLLA amphiphile in chlorinated solvents. As a consequence, most of the galactose content is certainly confined in the core of the fibers to minimize interaction with DMC thus explaining their irregular morphologies and micrometric diameters as observed by FE-SEM. Enzyme hydrolysis and water-contact-angle tests also go in behalf of such hypothesis, confirming that the sugar density on the fiber's surface is rather limited.

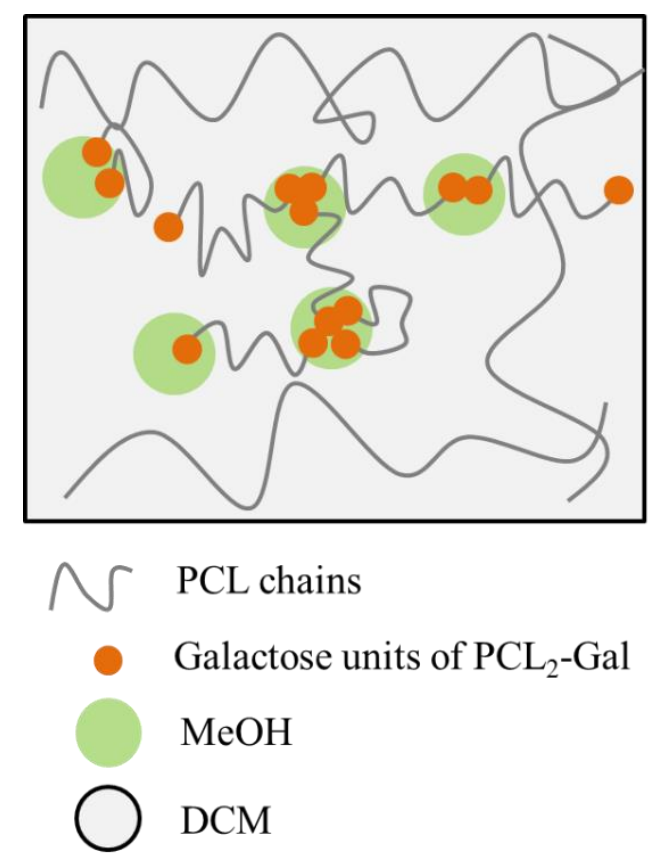

Figure 5. Schematic representation of the $\mathrm{PCL}_{2}-\mathrm{Gal}_{/} \mathrm{PCL}_{80}$ polymer organization in the $\mathrm{DCM} / \mathrm{MeOH} 4 / 1$ solvent mixture

In order to reduce or avoid the carbohydrate confinement in the fibers during electrospinning, alternative solvent systems should be employed. However few of the usual solvents combine $i$ ) a good solubility of both the carbohydrate and the PCL parts and ii) a good processing regarding electrospinning. Hence, an alternative approach to draw highly surface-decorated PCL fibers was further investigated by means of selective surface modification. 


\subsection{Surface-Functionalization of the f-PCL-N3 Fibers}

In a recent work we reported a simple and elegant way to obtain ultra-fine surfacedecorated azido-fibers. ${ }^{29}$ Briefly, using a classical electrospinning setup, a blend of azidefunctionalized low-molecular-weight $\mathrm{PCL}_{2}-\mathrm{N}_{3}$ and non-derived $\mathrm{PCL}_{80}$ in DCM/MeOH 4/1 solvent mixture was electrospun. The high electric field induced migration of the azide group to the surface of the fibers. These findings opened exciting perspectives towards versatile surface functionalization of the fibers by click chemistry.

Herein, we investigated the effectiveness of such surface functionalization with monosaccharides - galactose (Gal) and mannose (Man) - to access to new biomaterials with protein adhesion capacities. f-PCL- $\mathrm{N}_{3}-20,-40$, and -60 fibers were functionalized by heterogeneous click chemistry with propargyl- $\alpha$-D-mannoside and propargyl- $\beta$-Dgalactoside affording f-PCL $20-\mathrm{Man}_{\mathrm{S}}$, f-PCL $40-\mathrm{Man}_{\mathrm{S}}$ and f-PCL $60-\mathrm{Man}_{\mathrm{S}}$, and f-PCL $20-\mathrm{Gal}_{\mathrm{S}}$, f-PCL $40-\mathrm{Gal}_{\mathrm{S}}$ and f-PCL $60-\mathrm{Gal}_{\mathrm{S}}$, respectively. ATR-FTIR spectra of the azido fiber f-PCL$\mathrm{N}_{3}-20$ and its galactosylated counterpart $\mathrm{f}-\mathrm{PCL}_{20}-\mathrm{Gal}_{\mathrm{S}}$ are illustrated in Figure 6. The presence of sugars on the fibers is evidenced by the large peak at $3300 \mathrm{~cm}^{-1}$ assigned to stretching vibrations of hydroxyl groups as well as vibrations of $-\mathrm{N}-\mathrm{H}$ at $3744 \mathrm{~cm}^{-1}$. A peak at $\sim 1642 \mathrm{~cm}^{-1}$, corresponding to -C-O- stretching groups of monosaccharide, absent in native $\mathrm{PCL}_{80}$, was also noted. The characteristic peak of azide groups, at $2100 \mathrm{~cm}^{-1}$, indicates some remaining azido groups on the surface as well as inside the fibers after the sugar coupling. 


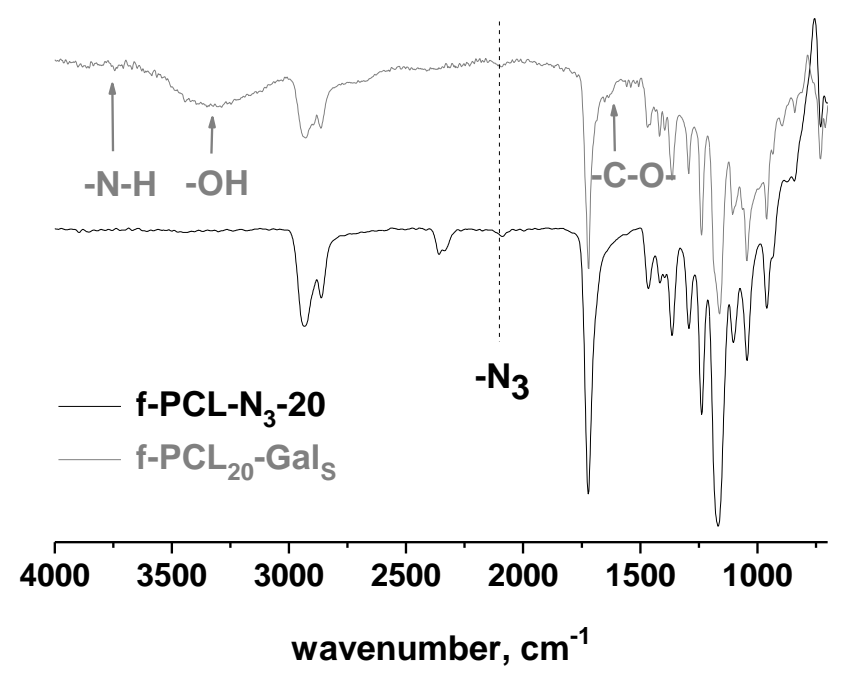

Figure 6. ATR-FTIR spectra of f-PCL-N $3-20$ (black line) and f-PCL ${ }_{20}-G_{\text {Gals }}$ (grey line) fibers

The sugar content introduced on the surface of the f-PCL-Gals and f-PCL-Man fibers was determined by the Dubois phenol-sulfuric acid assay. ${ }^{18,39}$ (see Table S1 Supplementary Information). As one would expect, the carbohydrate density at the surface increased with the amount of available azide groups in the f-PCL-N 3 fibers. Interestingly, it was however observed that the overall coupling yield remained constant, about $20 \mathrm{wt} \%$, for both galactose- and mannose- surface-functionalized fibers. In comparison with the bulk functionalization approach where 2-3 wt $\%$ only of the initial sugar amount was displayed at the surface of the fibers, click chemistry modification of azido-decorated fibers allows significantly higher functionalization with $20 \mathrm{wt} \%$ of grafted carbohydrate.

Wettability and hydrophilicity of the surface-functionalized f-PCL-Gals and f-PCLMans fibers were investigated using dynamic water-contact-angle measurements. As shown in Figure 7, the contact angle of f-PCL-Gals fibers is decreasing over time. In addition, the soaking rate of f-PCL-Gals fibrous membranes increased together with the galactose content at their surface. While the WCA of $\mathrm{f}-\mathrm{PCL}_{20}-\mathrm{Gal}_{\mathrm{S}}$ reached zero in about 
$60 \mathrm{~s}$, f-PCL $60-\mathrm{Gal}_{\mathrm{s}}$ fibers' WCA attained $0^{\circ}$ value in less than $3 \mathrm{~s}$. The gradual difference in the soaking rate was more accentuated for f-PCL-Mans samples where complete wettability was reached in 40, 12 and $7 \mathrm{~s}$ for f-PCL $20-\mathrm{Man}_{\mathrm{s}}$, f-PCL $40-\mathrm{Man}_{\mathrm{S}}$ and f-PCL60$\operatorname{Man}_{\mathrm{s}}$ fibers, respectively. These results, again support the efficient glycosylation of the fiber's surface. In addition, this glycosylation allowed to turn a hydrophobic material into a highly hydrophilic one. This point is very important in perspective of biological applications since one could expect hydrophilic materials to be more biocompatible and to favor interactions with proteins and cells.
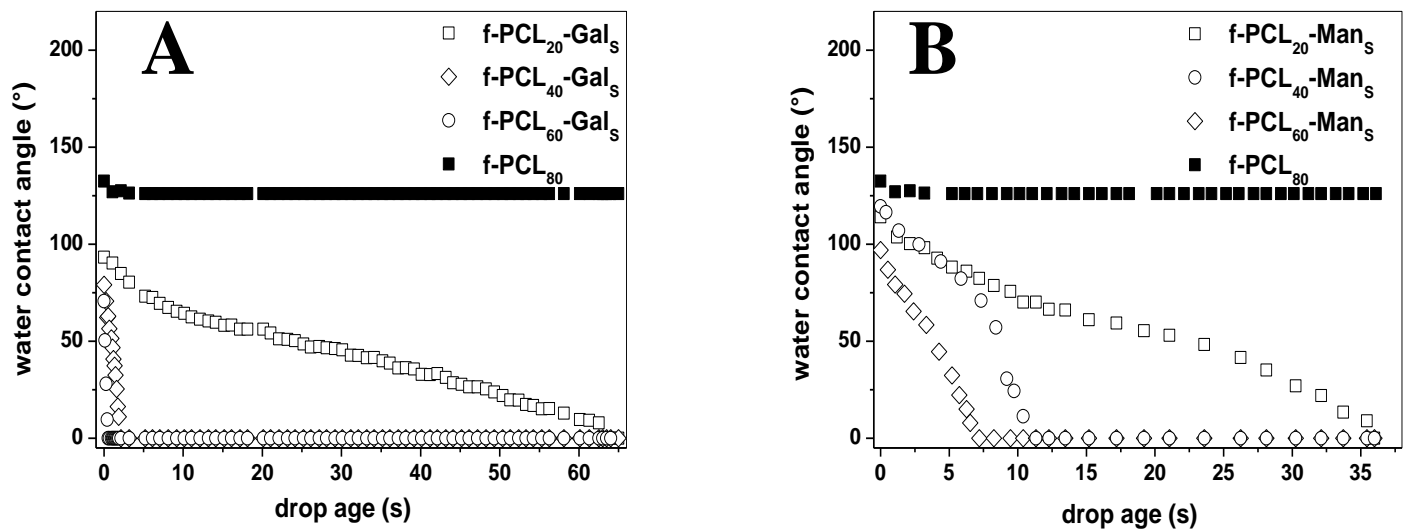

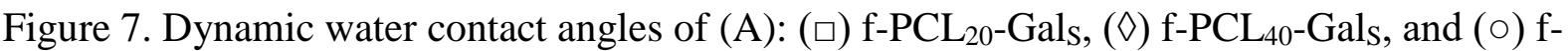
PCL $_{60}-\mathrm{Gal}_{\mathrm{S}}$ and (B): (口) f-PCL $20-\mathrm{Man}_{\mathrm{S}},(\diamond)$ f-PCL $\mathrm{P}_{40}-\mathrm{Man}_{\mathrm{S}}$, and (०) f-PCL $60-\mathrm{Man}_{\mathrm{S}}$ surfacefunctionalized fibers together with $(\mathbf{\square}) \mathrm{f}-\mathrm{PCL}_{80}$ as a reference

Bioavailability of carbohydrates was next investigated by enzyme-linked lectin assay (ELLA). Galactose and mannose-decorated fibers were respectively exposed to solutions of Concanavalin A-peroxidase conjugate (HRP-ConA) and Arachis hypogaea-peroxidase conjugate (HRP-PNA). Otman et al..$^{40}$ reported specific recognition of $\alpha$-D-mannose at the surface of polymeric nanoparticles by ConA, demonstrating that mannose groups, conjugated to the poly( $\varepsilon$-caprolactone), could bind the lectin. In this study, upon staining 
with the AEC chromogenic substrate, both f-PCL-Gals and f-PCL-Mans fibrous mats exhibited a positive coloration in presence of HPR-PNA and HRP-ConA lectins respectively (Figure 8). f-PCL-Mans fibers showed a very intense red color while f-PCL$\mathrm{Gal}_{\mathrm{S}}$ staining was less pronounced (see Figure 8). Such a difference between ConA and PNA binding efficiencies is not unexpected and $\mathrm{Wu}$ et al. ${ }^{41}$ previously observed that PNA lectin binds more strongly to lactose than to galactose, suggesting that this lectin needs a longer arm-spacer for a better carbohydrate recognition. Nonetheless, the control samples with non-functionalized f-PCL- $\mathrm{N}_{3}$ fibers showed no significant coloration under the same treatment, demonstrating that ELLA labeling is highly carbohydrate-specific.

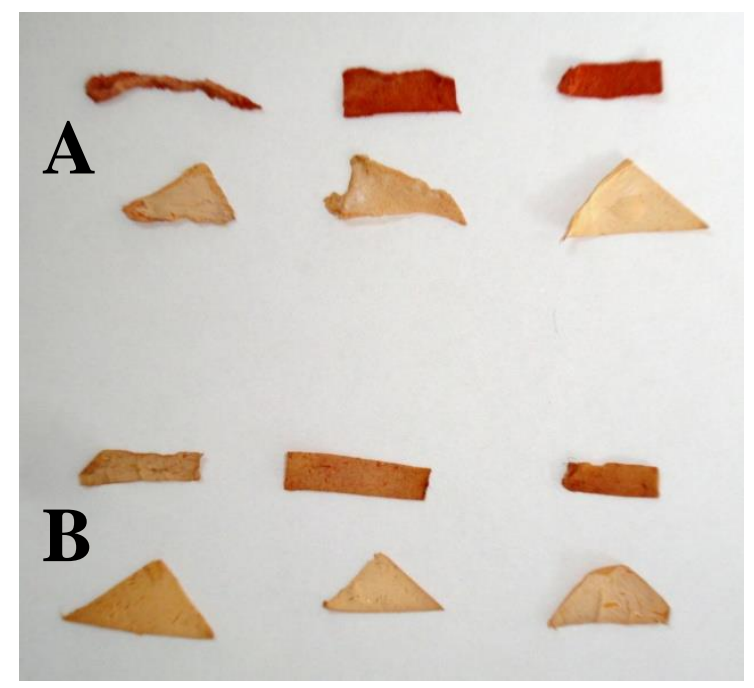

Figure 8. Image (from left to right) of ELLA assays on: (A) f-PCL $20-\mathrm{Man}_{\mathrm{S}}$, f-PCL40$\mathrm{Man}_{\mathrm{S}}$, and f-PCL $60-\mathrm{Man}_{\mathrm{S}}$ (B) f-PCL ${ }_{20}-\mathrm{Gal}_{\mathrm{S}}$, f-PCL $40-\mathrm{Gal}_{\mathrm{S}}$ and f-PCL $60^{-} \mathrm{Gal}_{\mathrm{S}}$ fibers. For each sample, top line corresponds to the positive test samples while bottom line matches the control samples.

Comparing the collected results of bulk- and surface-functionalized fibrous scaffolds, we could stress several important points. First of all, electrospun fibers derived from $\mathrm{PCL}_{2}-$ Gal and $\mathrm{PCL}_{2}-\mathrm{N}_{3}$ present quite different diameters and morphologies. f-PCL- $\mathrm{N}_{3}$, exhibited 
a regular diameter of $600 \mathrm{~nm}$ whatever the azide group content while the diameter of $\mathrm{f}$ PCL-Gal ${ }_{B}$ fibers was rather irregular and increased with the galactose content in the electrospinning blend. In addition, bulk-functionalized f-PCL ${ }_{20}-\mathrm{Gal}_{\mathrm{B}}$ fibers had a rather small sugar content at their surface $(\sim 3 \mathrm{wt} \%)$ compared with the surface-functionalized $\mathrm{f}$ $\mathrm{PCL}_{20}-\mathrm{Gal}_{\mathrm{S}}$ and f-PCL $20-\mathrm{Man}_{\mathrm{S}}$ fibers $(\sim 20 \mathrm{wt} \%)$. Such a difference might be explained by the different solubility of $\mathrm{PCL}_{2}-\mathrm{N}_{3}$ and $\mathrm{PCL}_{2}-\mathrm{Gal}$ in the solvent system used for electrospinning. Indeed, $\mathrm{PCL}_{2}-\mathrm{N}_{3}$ is hydrophobic and totally soluble in DCM/MeOH. On the contrary, $\mathrm{PCL}_{2}-\mathrm{Gal}$ is amphiphilic and forms aggregates in the same solvent system as evidenced by DLS. The polymer probably adopts a conformation in which the sugar is confined in the core of the aggregates to minimize interactions with the solvent. Accordingly, the galactose residues are predominantly entrapped in the core of the fiber and very few are available at the surface for protein binding.

On the contrary, f-PCL-N $\mathrm{N}_{3}$ electrospun fibers presented high density of azide groups at their surface as a response to the high electric field applied. Functionalization by click chemistry has further allowed the glycosylation of $20 \mathrm{wt} \%$ of sugar at the fiber surface and transformed hydrophobic PCL fibers into hydrophilic and bioactive PCL scaffolds. Despite the effectiveness of surface functionalization by $\mathrm{CuAAC}$, the use of copper catalysts can be an obstacle for medical applications. To overcome this drawback, strained alkynes might be used to realize copper-free click conjugation. ${ }^{42}$

\section{CONCLUSIONS}

Bulk- and surface-glycosylation of electrospun fibers were explored and their effectiveness was compared. Electrospun blend of $\mathrm{PCL}_{2}-\mathrm{Gal}$ and $\mathrm{PCL}_{80}$ resulted in poorly surfacedecorated fibers with moderately increased hydrophilicity. Yet, surface functionalization by click chemistry of f-PCL- $\mathrm{N}_{3}$ ultra-fine fibers with galactose and mannose moieties was 
rewarded with successful sugar conjugation and high hydrophilicity of functionalized fibers. Enzyme-linked lectin assays of the fibrous mats confirmed the ability of carbohydrate to interact with specific lectins, indicating the biological potential of these scaffolds in tissueengineering.

\section{SUPPORTING INFORMATION}

Additional information about synthesis of propargyl- $\beta$-D-galactose and propargyl- $\alpha$-Dmannose accompanied with their NMR and MALDI-TOF mass spectroscopy, NMR and MALDI-TOF analyses of $\mathrm{PCL}_{2}-\mathrm{Gal}$, as well as tabulation of the Dubois colorimetric results of surface-functionalized f-PCL-Gals and f-PCL-Mans fibers. This material is available free of charge via the Internet at http://pubs.acs.org

\section{Corresponding Author}

Sébastien Fort*

Centre de Recherches sur les Macromolécules Végétales, UPR CNRS 5301, BP53, 38041 Grenoble Cedex 9, France.

E-mail: sebastien.fort@cermav.cnrs.fr

\section{Author Contributions}

All authors have given approval to the final version of the manuscript.

\section{Funding Sources}

This research was supported by the grant of Institut Carnot "Polynat" and the MNERT PhD grant N²010/A8 to Anica Lancuški. 


\section{AKNOWLEDGEMENTS}

The authors gratefully acknowledge Rachel Martin for her expert help and technical assistance in FESEM microscopy, Dr. Bernard Priem for helpful discussions on ELLA tests, Stéphanie Boullanger her technical assistance in mass spectrometry analysis, Dr. Christophe Travelet for his technical assistance in dynamic light scattering measurements and laboratory NanoBio and Hugues Bonnet for providing us facilities for contact angle measurements. We also thank the Institute Carnot "Polynat" for financial support and the MNERT for PhD grant $N^{\circ} 2010 / A 8$ to Anica Lancuški.

\section{ABBREVIATIONS}

PCLso poly( $\varepsilon$-caprolactone) $M_{n} 80000 \mathrm{~g} / \mathrm{mol} ;$ PCL2 $\alpha, \omega$-diol-poly( $\varepsilon$-caprolactone) $M_{n} 2$ $000 \mathrm{~g} / \mathrm{mol} ;$ PCL2-N3 $\alpha, \omega$-azido-poly( $\varepsilon$-caprolactone); PCL2-Gal $\alpha, \omega$-galactoside-poly( $\varepsilon$ caprolactone); f-PCLso poly( $\varepsilon$-caprolactone) fibers; f-PCL-N3-X fibers containing $X=20,40$ and $60 \mathrm{wt} \%$ of PCL-N 3 and (100-X) wt\% of PCL 80 ; f-PCLx-Gals bulk-functionalized fibers containing X=20 and $40 \mathrm{wt} \%$ of $\mathrm{PCL}_{2}-\mathrm{Gal}$ and $(100-\mathrm{X}) \mathrm{wt} \%$ of PCL 80 ; f-PCLx-Gals surfacefunctionalized f-PCL-N 3 -X fibers with propargyl- $\beta$-D-galactose; f-PCLx-Mans surfacefunctionalized f-PCL-N $\mathrm{N}_{3}-\mathrm{X}$ fibers with propargyl- $\alpha$-D-mannose.

\section{REFERENCES}

1. Sell, S. A.; Wolfe, P.S.; Garg, K.; McCool, J.M.; Rodriguez, I. A.; Bowlin, G. L. Polymers 2010, 2, 522-553.

2. Barnes, C. P.; Sell, S. A.; Boland, E. D.; Simpson, D. G.; Bowlin, G. L. Adv. Drug Deliv. Rev. 2007, 59, 1413-1433.

3. Lalani, R.; Liu, L. Biomacromolecules 2012, 13, 1853-1863. 
4. Mickova, A.; Buzgo, M.; Benada, O.; Rampichova, M.; Fisar, Z.; Filova, E.; Tesarova, M.; Lukas, D.; Amler, E. Biomacromolecules 2012, 13, 952-962.

5. Shalumon, K. T.; Anulekha, K. H.; Chennazhi, K. P.; Tamura, H.; Nair, S. V.; Jayakumar, R. Int. J. Biol. Macromol. 2011, 48, 571-576.

6. Ghasemi-Mobarakeh, L.; Prabhakaran, M. P.; Morshed, M.; Nasr-Esfahani, M. H.; Ramakrishna, S. Mater. Sci. Eng., C 2010, 30, 1129-1136.

7. Seyednejad, H.; Ji, W.; Yang, F.; van Nostrum, C. F.; Vermonden, T.; van den Beucken, J. J. J. P.; Dhert, W. J. A.; Hennick, W. E.; Jansen, J. A. Biomacromolecules 2012, 13, $3650-3660$.

8. Xie, J.; Michael, P. L.; Zhong, S.; Ma, B.; MacEwan, M. R.; Lim, C. T. J. Biomed. Mater. Res., Part A 2012, 100A, 929-938.

9. Chung, A. S.; Hwang, H. S.; Das, D.; Zuk, P.; McAllister, D. R.; Wu, B. M. J. Biomed. Mater. Res., Part B 2012, 100B, 274-284.

10. Yuan, W.; Li, C.; Zhao, C.; Sui, C.; Yang, W.-T.; Xu, F.-J.; Jie, M. Adv. Funct. Mater. 2012, 22, 1835-1842.

11. Choong, C.; Foord, J. S.; Griffiths, J.-P.; Parker, E. M.; Baiwen, L.; Bora, M.; Moloney, M. G. New J. Chem. 2012, 36, 1187-1200.

12. Grafahrend, D.; Calvet, J. L.; Klinkhammer, K.; Salber, J.; Dalton, P. D.; Moller, M.; Klee, D. Biotechnol. Bioeng. 2008, 101, 609-621.

13. Fleischmann, S.; Hinrichs, K.; Oertel, U.; Reichelt, S.; Eichhorn, K.-J.; Voit, B. Macromol. Rapid Commun. 2008, 29, 1177-1185.

14. Zheng, J.; Liu, K.; Reneker, D. H.; Becker, M. L. J. Am. Chem. Soc. 2012, 134, 17274 17277.

15. Zhao, G.-L.; Hafrén, J.; Deiana, L.; Córdova, A. Macromol. Rapid Commun. 2010, 31, $740-744$. 
16. Krouit, M.; Bras, J.; Belgacem, M. N. Eur. Polym. J. 2008, 44, 4074-4081.

17. Xu, N.; Lu, F.-Z.; Du, F.-S.; Li, Z.-C. Macromol. Chem. Phys. 2007, 208, 730-738.

18. Galgali, P.; Puntambekar, U.; Gokhale, D.; Varma, A. Carbohydr. Polym. 2004, 55, 393399.

19. Gentsch, R.; Pippig, F.; Nilles, K.; Theato, P.; Kikkeri, R.; Maglinao, M.; Lepenies, B.; Seeberger, P.H.; Broner, H.G. Macromolecules 2010, 43, 9239-9247.

20. Chua, K.-N.; Lim, W.-S.; Zhang, P.; Lu, H.; Wen, J.; Ramakrishna, S.; Leong, K. W.; Mao, H.-Q. Biomaterials 2005, 26, 2537-2547.

21. Kim, T. G.; Park, T. G. Biotechnology Progress 2006, 22, 1108-1113.

22. Fraser, C.; Grubbs, R. H. Macromolecules 1995, 28, 7248-7255.

23. Shukla, R. K.; Tiwari, A. Carbohydr. Polym. 2012, 88, 399-416.

24. Grafahrend, D.; Heffels, K.-H.; Beer, M.V.; Gasteier, P.; Moller, M.; Boehm, G.; Dalton, P. D.; Groll, J. Nature Mater. 2011, 10, 67-73.

25. Grafahrend, D.; Calvet, J. L.; Salber, J; Dalton P.D.; Moeller M.; Klee, D. J. Mater. Sci. Mater. Med. 2007, 19, 1479-1484.

26. Klinkhaller, K.; Bockelmann, J.; Simitzis, C.; Brook, G. A.; Grafahrend, D.; Groll, J.; Moller, M.; Mey, J.; Klee, D. J. Mater. Sci. Mater. Med. 2010, 21, 2637-2651.

27. Grafahrend, D.; Heffels, K.-H.; Moller, M.; Klee, D.; Groll, J. Macromol. Biosci. 2010, $10,1022-1027$.

28. Losel, R.; Grafahrend, D.; Moller, M.; Klee, D. Macromol. Biosci. 2010, 10, 1177-1183.

29. Lancuški, A.; Fort, S.; Bossard, F. ACS Appl. Mater. Interfaces 2012, 4, 6499-6504.

30. Provencher, S. W. Macromol. Chem. Phys. 1979, 180, 201-209.

31. Dal Bó, A. G. ; Soldi, V. ; Giacomelli, F. C.; Travelet, C.; Jean, B.; Pignot-Paintrand, I.; Borsali, R.; Fort, S. Langmuir 2012, 28, 1418-1426.

32. Heller, W. J. Phys. Chem. 1965, 69, 1123-1129.

33. Sharma, S.; Patel, P. B.; Patel, R. S.; Vora, J. J. E-J. Chem. 2007, 4, 343-349. 
34. Mehra, R. Proc. Indian Acad. Sci. (Chem. Sci.) 2003, 115, 147-154.

35. Dubois, M.; Gilles, K. A.; Hamilton, J. K.; Rebers, P. A.; Smith, F. Anal. Chem. 1956, 28, $350-356$.

36. Liu, Y.; Ma, G.; Fang, D.; Xu, J.; Zhang, H.; Nie, J. Carbohydr. Polym. 2011, 83, 10111015.

37. Yu, D.-G.; Branford-White, C.; Williams, G. R.; Bligh, S. W. A.; White, K.; Zhu, L.-M.; Chatterton, N. P. Soft Matter 2011, 7, 8239-8247.

38. Gentsch, R.; Pippig, F.; Schmidt, S.; Cernoch, P.; Polleux, J.; Borner, H.G. Macromolecules 2011, 44, 453-461.

39. Bech, L.; Lepoittevin, B.; El Achhab, A.; Lepleux, E.; Teule-Gay, L.; Boisse-Laporte, C.; Roger, P. Langmuir 2007, 23, 10348-10352.

40. Otman, O.; Boullanger, P.; Drockenmuller, E.; Hamaide, T. Beilstein J. Org. Chem. 2010, $6,1-7$.

41. Wu, P.; Chen, X.; Hu, N.; Tam, U.C.; Blixt, O.; Zettl, A.; Bertozzi, C.R. Angew. Chem. Int. Ed. 2008, 47, 5022-5025.

42. Codelli, J. A.; Baskin, J. M.; Agard, N. J.; Bertozzi, C. R. J. Am. Chem. Soc. 2008, 130, 11486-11493. 
Table of contents:

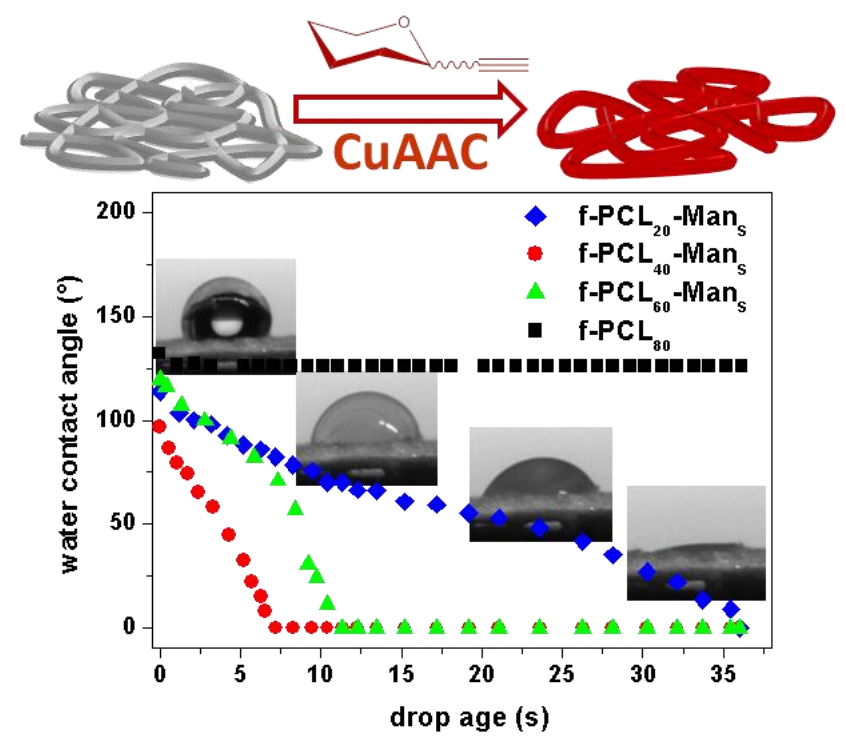

